\title{
Study of Growth Rhythm of Non-Energy-Plant Stevia Rebaudiana Hemsl in Seedling-Growing Stage in Hexi Region, Gansu Province
}

\author{
Sun Hongyi \\ Cold and Arid Regions Environmental and Engineering \\ Research Institute \\ Chinese Academy of Sciences \\ Lanzhou, China \\ e-mail: sunhy569@1zb.c.cn
}

\author{
Dong Haitao \\ Cold and Arid Regions Environmental and Engineering \\ Research Institute \\ Chinese Academy of Sciences \\ Lanzhou, China \\ e-mail: haitao_dong@yeah.net
}

\begin{abstract}
In this paper, seedling of non-energy-plant Stevia rebaudiana Hemsl in greenhouse is designed as the research subject. After its plant height, fresh weight, root length, leaf number, soil moisture content and other indexes are measured, seedling Stevia is found in germination period, slow growing period after germination, rapid growing period and then field transplanting period. In the meantime, root length of Stevia shows a linear increasing tendency with increasing growing time; plant height and fresh weight show an exponential increasing tendency with increasing growing time; leaf number shows a linear increasing tendency with increasing growing time; fresh weight and plant height present a linear relationship, that is, the higher the plant height is, the heavier the fresh weight is and the larger the plant biomass is; plant height and root length present a logarithmic function relationship; fresh weight and root length present an exponential relationship, namely, plant height and leaf number above the ground mainly develop and root length does not change greatly when root length increases to $30 \mathrm{~mm}$; and soil surface moisture content should be above $20 \%(2 \mathrm{~mm})$ consistently so as to meet the moisture condition for the germination of Stevia in greenhouse.
\end{abstract}

Keywords-Stevia rebaudiana Hems; seedling; growth rhythm; seedling-growing measure; soil moisture content

\section{INTRODUCTION}

Growth rhythm [1] refers to the increase of length, size, volume or weight of a plant with changing time through plant cell, organ or the whole growth of this plant under certain geographical and climatic conditions. In crop cultivation system, growth rhythm defines the important time nodes of crop fertilization, irrigation, gathering and harvesting, breeding environment control and yield estimation. Generally speaking, plant growth rhythm may show S-shaped growth law, exponential growth law, linear growth law and other growth laws [24].

The sweetness of Stevia is 300 times of that of glucose [5]. Its sweet component is two terpene glycosides nonglucose, so it is called as a non-energy-plant. It is suitable for population who suffer from diabetes, hypertension and hyperlipidemia. In China, Stevia has been greatly spread as a cash crop since 1980's [6] and is mainly planted in
Anhui, Shandong, Heilongjiang and other provinces [4]. In these plantation plots, corresponding standards of cultivation techniques have been improved continuously. In the northeast, Wang and others [7] proposed many high yield cultivation techniques, including cultivation under glass, rational close planting, timely terminal bud removing, disease prevention and others. In Lengliang irrigation area in Hexi, Gansu, Zhou and others [6] analyzed the adaptability, antireversion force, yielding ability, income-improving ability, cultivation friendliness and other advantages of Stevia cultivation, demonstrated the application, prospect, final yield and maximum benefit of Stevia, and put forward the cultivation technical specifications in line with Stevia cultivation in this area; $\mathrm{Li}$ and others [8] suggested high quality and efficient cultivation techniques and measures in the aspects of seed treatment, sowing in due course, greenhouse management, scientific seedling lifting and so on. In the southwest of Shandong, Li and others [9] proposed key points suitable for standardized cultivation of Stevia so as to forbid the use of repeatedly cropped land, day and night temperature control in seedling greenhouse, transplanting density and other techniques. After the popularization of these measures, the yield increased by $45.2 \mathrm{~kg}$ per mu and the net income increased by $512.8 y u a n$. In winter wheat area of the North China Plain, Tan and others [10] summarized a set of winter wheat- Stevia double cropping system. In Wuhan, Hubei, Liu and others [11] introduced Stevia and adopted the plastic film mulching cultivation. Then, the physical and chemical properties of soil have been improved, the ecological environment of farmland has been optimized, the seed germination rate has been increased by $200 \%$, the seeding stage is $40 \mathrm{~d}$ earlier, the phonological period is $15 \mathrm{~d}$ earlier or so, and dry weight per plant has been increased by $50 \%-85 \%$. In respect of Stevia under glass, $\mathrm{Xu}$ and others [12] found that black plastic film mulching effectively restrains weed growth and harvest period of Stevia is $20 \mathrm{~d}$ earlier. With regard to the influence of plant hormones on the proliferating and rooting of Stevia, Zhang and others [13] deemed that when the culture medium is $\mathrm{MS}+\mathrm{BA} 0.4 \mathrm{mg} / \mathrm{L}+\mathrm{NAA}$ $0.1 \mathrm{mg} / \mathrm{L}$, the proliferation multiple of adventitious buds is up to 14.4 times; and when the culture medium is 
MS+IBA $0.25 \mathrm{mg} / \mathrm{L}$, the rooting rate reaches $85.7 \%$. In general, mere planting of one cash crop is not conducive to efficient production and cultivation and will not bring high economic benefits for farmers, so every plot around the country all has explored multi-crop cultivation in varying degrees [14]. Considering summer-planted Stevia in Jining, Shandong is troubled with short growth cycle and low yield, Zheng [15] explored the key cultivation technique of planting-after-harvest model including Stevia, Chinese cabbage, radish, garlic, onion, cabbage and potato. However, reports of growth rhythm of Stevia in seedlinggrowing stage are still rare at present.

Thousand grain weight of Stevia is about $0.3 \mathrm{~g}$, and its seed is with hard hairs, so Stevia in Hexi, Gansu should be through the greenhouse seedling-growing stage $[4,6,16]$ before it is transplanted to the field. Stevia in greenhouse seedling-growing stage and in early growth stage after its transplantation shows its characteristic: it grows slowly in early stage and then grows rapidly later. Farmers who do not understand this characteristic of Stevia tend to mistakenly believe that Stevia's failure in adapting itself to the local agricultural production incurs its tardy growth, thus causing farmers to destroy seedlings and replant other crops. Therefore, slow and rapid growth characteristic of Stevia in greenhouse seedling-growing stage is studied in this paper to provide a theoretical basis for Stevia planting and to provide data for seedling strengthening, soil moisture management and formulation of technical specification.

\section{MAERIALS AND METHODS}

\section{A. Overview of study site}

The study site is located in Daya Village, Yanuan Country, Linze County, Heihe River Basin in the middle of Hexi Corridor, Gansu Province. Its geographic coordinates are $39^{\circ} 17^{\prime} 7^{\prime \prime} \mathrm{N}, 100^{\circ} 11^{\prime} 27^{\prime \prime}$ "E. The average annual rainfall is $116.8 \mathrm{~mm}$ and the annual evaporation capacity is $2390 \mathrm{~mm}$, more than 20 times of rainfall. The average annual temperature is $7.6^{\circ} \mathrm{C}$ with the highest as $39.1^{\circ} \mathrm{C}$ and the lowest as $-27^{\circ} \mathrm{C}$. The accumulated temperature $\geq 10^{\circ} \mathrm{C}$ is $3088^{\circ} \mathrm{C}$ and the frost free period is $165 \mathrm{~d}$. The northwest wind dominates, windy and sandy storms occur mostly from March to May, the average annual wind speed is $3.2 \mathrm{~m} \bullet \mathrm{s}-1$, and the average annual gale days with wind above scale 8 are $15 \mathrm{~d}$. The annual hours of sunshine are $3045 \mathrm{~h}$. The depth of frozen soil is about $1.0 \mathrm{~m}$. The soil nutrient condition of study site is as follows: $11.43 \mathrm{~g} / \mathrm{kg}$ organic matter, $0.96 \mathrm{~g} / \mathrm{kg}$ total nitrogen, $71.34 \mathrm{mg} / \mathrm{g}$ Alkali hydrolysable nitrogen, $116.97 \mathrm{mg} / \mathrm{kg}$ rapidly available phosphorus, and $200 \mathrm{mg} / \mathrm{kg}$ rapidly available kalium.

\section{B. Study arrangement}

Test time: March 5, 2014- May 5, 2014.

Preparation of seeds: Variety "Huinong 3" is adopted as seeds of Stevia with thousand grain weight being $0.362 \mathrm{~g}$; the used seed amount is $100 \mathrm{~g} / \mathrm{mu}$. Seeds should be soaked in warm water for 24 hours before sowing, then water of soaked seeds should be drained totally and 3 times of dry soil should be added to mix with seeds.
Seedbed preparation: Seedbed with good permeability, convenient drainage and irrigation, rich organic matter and natural, loose\& medium soil is preferred. The rectangular size of experimental vaulted greenhouse is $36 \mathrm{~m} \times 9 \mathrm{~m}$, and the seedbed is divided into small polls in size of $3 \mathrm{~m} \times 4 \mathrm{~m}$ (Fig. 1). 1-2 days before sowing, the seedbed should be raked, leveled and watered, and mixed seeds should be evenly spread in seedbed. Then plastic film should cover the ground immediately and outer film of vaulted greenhouse should be fixed well. When $60 \%$ of seeds come up out of the ground, the plastic film on the ground should be removed.

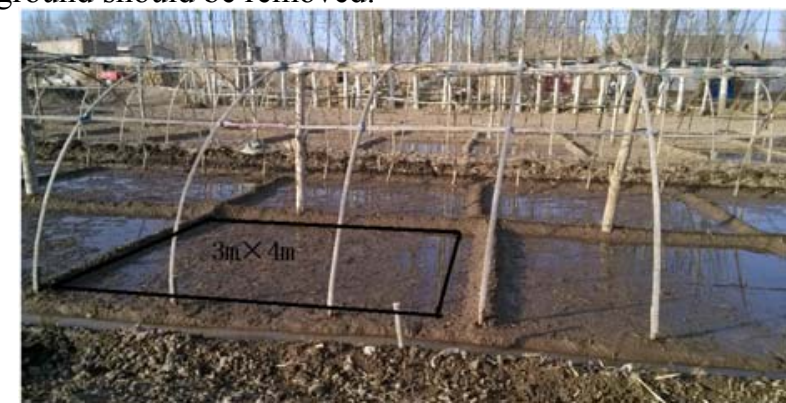

Figure 1. Experimental vaulted greenhouse

Watering: When a seedling grows out 2 pairs of true leaves, the soil moisture content of seedbed should be checked every day and night, and timely watering is a must to keep the seedbed moist. When a seedling grows out 3 pairs of true leaves, the watering cycle is 15 days and the seedling should be soaked each time.

\section{Data acquisition}

Measurement data: The date of germination, the date of seedling emergence; germination number, seedling height, root length, leaf number every three days.

Weight data: 10 plants are randomly collected every three days, and fresh weight and dry weight of each plant are measured.

Soil moisture content data: Soil auger drying method is adopted to measure the soil moisture content. Soil moisture contents (weight \%) are measured respectively at points $0 \mathrm{~cm}, 10 \mathrm{~cm}, 20 \mathrm{~cm}, 30 \mathrm{~cm}, 40 \mathrm{~cm}$ and $50 \mathrm{~cm}$ below the ground. For each layer, 3 measurements are made. Soil moisture content (weight $\%)=($ Original soil weight - dried soil weight )/ dried soil weight $\times 100 \%$.

\section{Data analysis}

1. Soil moisture content (depth of water layer $\mathrm{mm})=$ depth of soil layer $(\mathrm{mm}) \times$ Soil moisture content (weight $\%) \times 10$.

2. Pre-treatment of test data is conducted via SPSS 17.0. Fitting curve of data regression analysis is completed via software Origin 9.0. Contour map of soil moisture content is drawn via software Surfer11.0.

\section{RESULTS AND ANALYSES}

\section{A. Root length variations with changing time}

Seeds of Stevia were sowed on March 2 (Fig. 2: Point A). 9d later, embryos started to appear white (Fig. 2: Point B). On March 14, seedlings grew out (Fig. 2: Point C). Then, root growth began. Root length was measured from March 15. The test showed that there is a linear increasing 
relationship between root length of plants and increasing time.

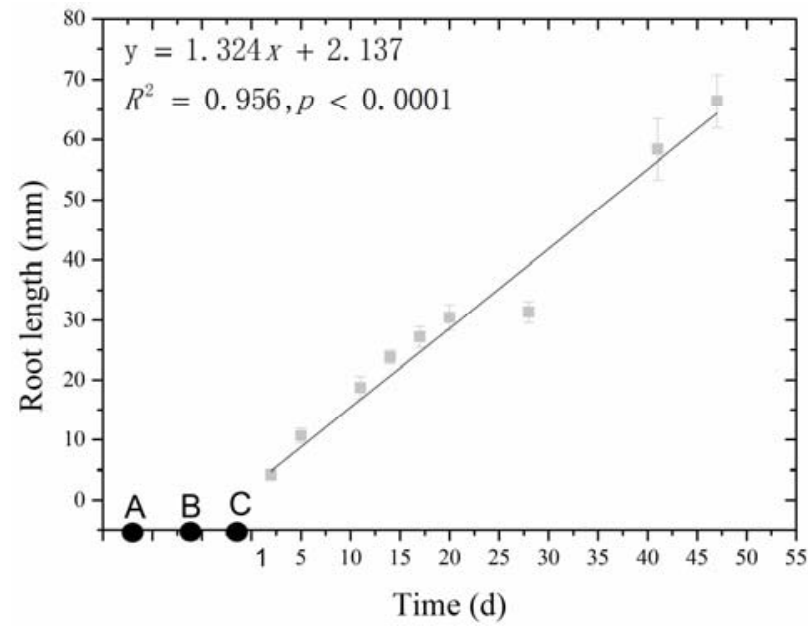

Figure 2. The relationship between root length of Stevia and increasing time

\section{B. Plant height variations with changing time}

Since seeds of Stevia were sowed on March 2, they started to germinate 12 days later. In early stage 1-30d, the plant height grew slowly; in later stage $30-50 \mathrm{~d}$, the plant height grew rapidly, thus showing a "slow-rapid" characteristic (Fig. 3). There is an exponential increasing relationship between plant height and increasing time.

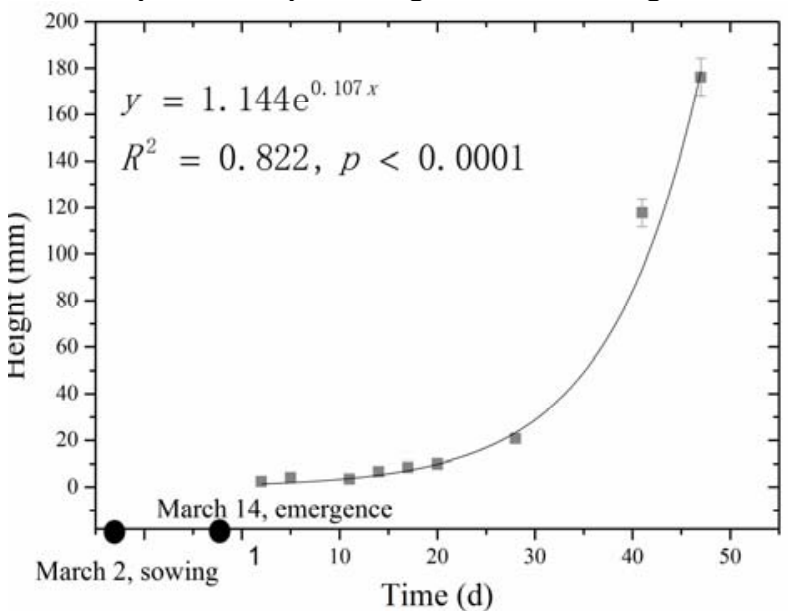

Figure 3. The relationship between plant height of Stevia and increasing time

\section{Fresh weight variations with changing time}

The relationship between fresh weight (above and below the ground) and increasing time (Fig. 4) is similar to that between plant height and increasing time. In early stage 1-30d, the fresh weight grew slowly; in later stage $30-50 \mathrm{~d}$, the fresh weight grew rapidly, thus showing a "slow-rapid" characteristic. There is an exponential increasing relationship between seedling weight and increasing time.

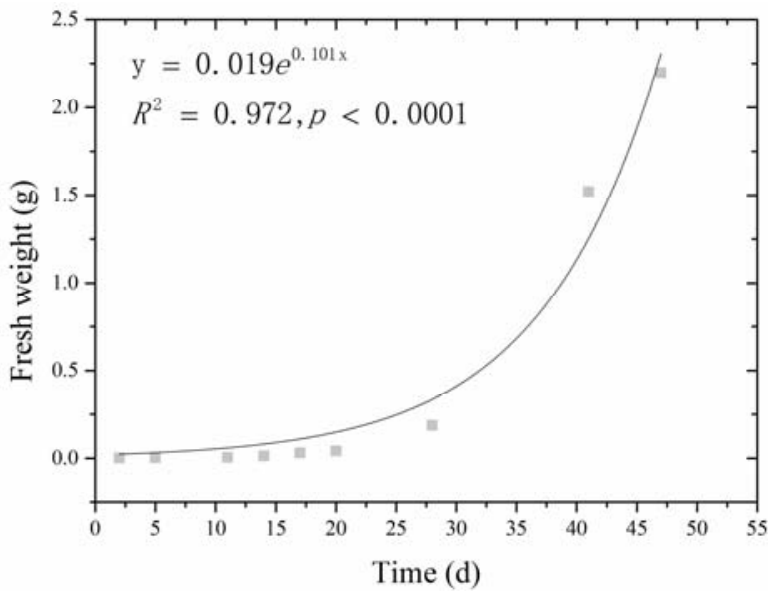

Figure 4. The relationship between fresh weight of seedling Stevia and increasing time time

\section{Opposite leaf number variations with changing}

Stevia has opposite leaves. $12 \mathrm{~d}$ after sowing, seedlings started to grow out and cotyledons emerged. $7 \mathrm{~d}$ later, the second pair emerged. Therefore, the whole seedling growth period lasted in $50 \mathrm{~d}$ (Fig. 5). There is a linear increasing relationship between leaf number and increasing time. Every 5d or so, a pair of new cotyledons added.

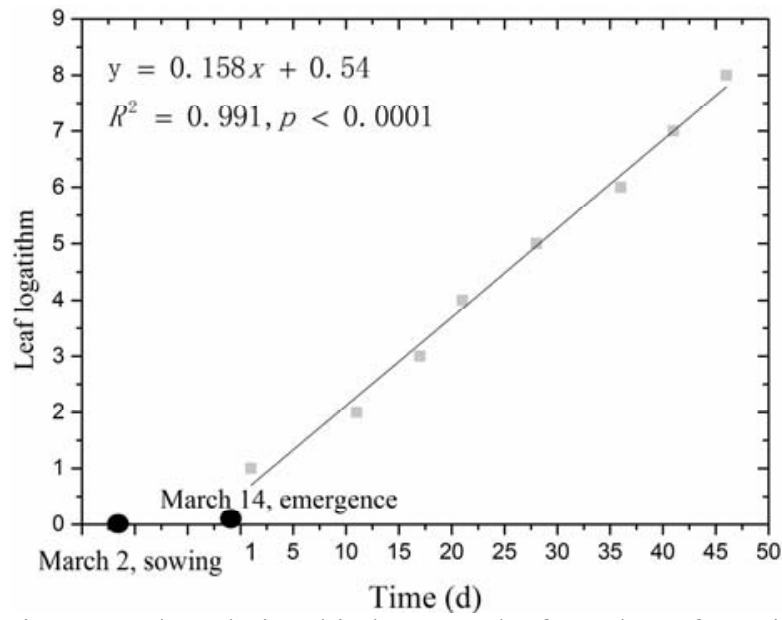

Figure 5. The relationship between leaf number of Stevia and increasing time

\section{E. Soil moisture variations of stevia in seedling} stage

The greenhouse temperature and soil moisture content are important factors that have influence on seedling emergence and growth of Stevia. The best condition is when the greenhouse temperature reaches $25^{\circ} \mathrm{C}$ and the ground moisture is kept moist. 15 consecutive days from greenhouse watering on March 19 are one irrigation cycle. As can be seen from changes of soil moisture content within $50 \mathrm{~cm}$ below the ground (Fig. 6), the average soil moisture content $0-10 \mathrm{~cm}$ below the ground is $21.8 \%$ $(2.18 \mathrm{~mm})$, the average soil moisture content $10-20 \mathrm{~cm}$ below the ground is $24.84 \%(2.484 \mathrm{~mm})$, the average soil moisture content $20-30 \mathrm{~cm}$ below the ground is $25.97 \%(2.597 \mathrm{~mm})$, the average soil moisture content 30 $40 \mathrm{~cm}$ below the ground is $22.79 \%(2.279 \mathrm{~mm})$, and the average soil moisture content $40-50 \mathrm{~cm}$ below the ground 
is $21.8 \%(2.18 \mathrm{~mm})$. The average soil moisture content every $10 \mathrm{~cm}$ within $50 \mathrm{~cm}$ below the ground is $23.74 \%$ $(2.37 \mathrm{~mm})$. Changes of soil moisture content within $20 \mathrm{~cm}$ below the ground are faster than those within other depths. Therefore, the condition for germination of Stevia in greenhouse is to keep surface soil moisture content above $20 \%(2 \mathrm{~mm})$.

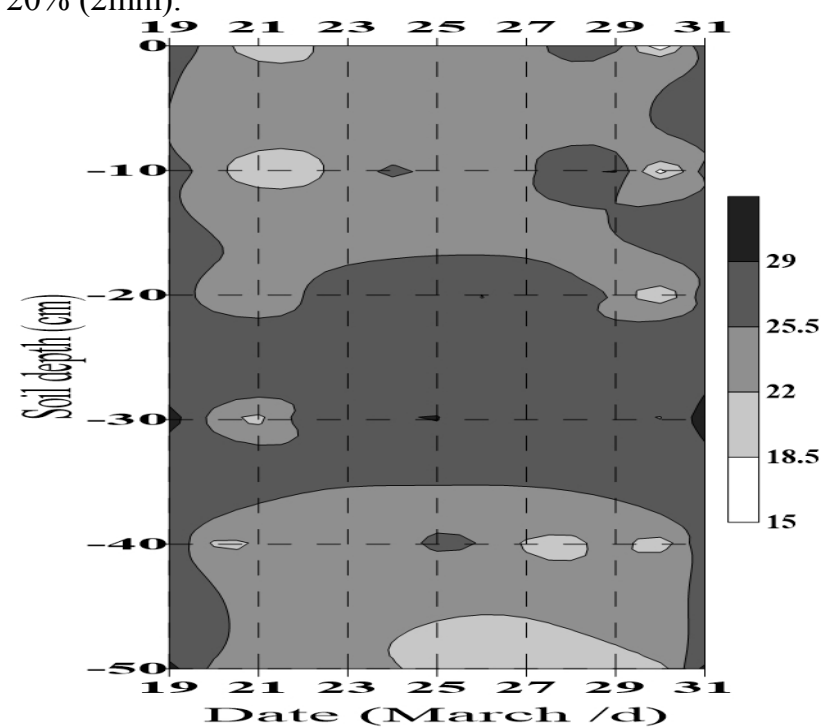

Figure 6. Soil moisture changes and its contour map of seedling Stevia in greenhouse in a watering cycle

F. Correlation among plant height, root length and seedling fresh weight

As regards Stevia in seedling stage, seedling fresh weight and plant height (Fig.7:A) present a linear function relationship, that is, the higher the plant height is, the heavier the fresh weight is and the larger the plant biomass is; plant height and root length (Fig. 7:B) present a logarithmic function relationship; fresh weight and root length (Fig.7:C) present an exponential function relationship, namely, plant height and leaf number above the ground mainly develop and root length does not change greatly when root length increases to $30 \mathrm{~mm}$.
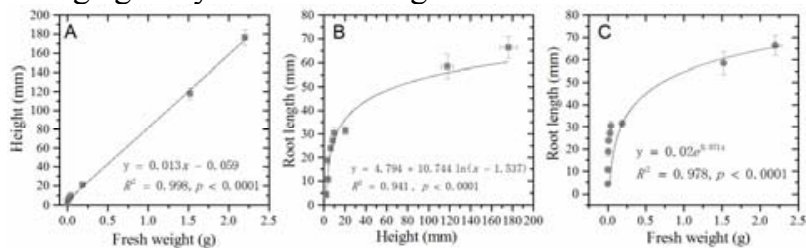

Figure 7. Correlation among plant height, root length and seedling fresh weight

\section{SUMMARY AND DISCUSSION}

Generally speaking, growth stages of plants include germination stage, rapid growth stage, blossom stage and seed maturation stage. However, growth stages of Stevia are germination stage in seedling period, slow growth stage after germination, rapid growth stage, slow seedling growth stage after transplantation into field, rapid growth stage, blossom stage and seed maturation stage. Data of this study showed that seeds began to germinate and appeared white $12 \mathrm{~d}$ after sowing; seedlings grew slowly after emergence [17] and grew rapidly 30d later; and then main stems produced branches and leaf number added [18], which caused the growth rhythm of Stevia 55d earlier. At this moment, leaf number of each plant reached 4 pairs and plant height was up to $10 \mathrm{~cm}$. During this stage, root length and growth time present a linear increasing relationship; plant height, fresh weight and growth time present an exponential increasing relationship; leaf number and growth time present a linear increasing relationship; fresh weight and plant height present a linear relationship, that is, the higher the plant height is, the heavier the fresh weight is and the larger the plant biomass is; plant height and root length present a logarithmic function relationship; fresh weight and root length present an exponential relationship, namely, plant height and leaf number above the ground mainly develop and root length does not change greatly when root length increases to $30 \mathrm{~mm}$. The above discoveries are in line with study results on growth conditions of Stevia by Ramesh, Singh and others [19].

A lot of research on growth rhythm of main-rootplants indicated that [20-22] changes of later root growth do not exhibit any linear rules and changes of root length are more than $20 \mathrm{~m}$. In this study, with Stevia as a fibrousroot-plant, root length and growth time present a linear increasing relationship. After $150 \mathrm{~d}$ of growth, its root length might be $20 \mathrm{~cm}$. This to certain degree can explain that fibrous roots of Stevia spread in the $20 \mathrm{~cm}$ spatial range. This discovery, different from root length distribution of general plants, to certain extent confirms the conclusion made by Chalapathi and others [23] that the optimal field-plantation spatial range of Stevia is $30 \mathrm{~cm}$.

The origin of Stevia is with high underground water level, moist, and does not cause waterlogging [17]. Therefore, Stevia is not vulnerable to water stress. The daily soil evapotranspiration is $5.75 \mathrm{~mm}$. In study of Stevia in Brazil [24]: within 0-25d, the field evapotranspiration is $6.66 \mathrm{~mm} / \mathrm{d}$; within $26-50 \mathrm{~d}$, the field evapotranspiration is $5.11 \mathrm{~mm} / \mathrm{d}$; and within $51-75 \mathrm{~d}$, the field evapotranspiration is $5.49 \mathrm{~mm} / \mathrm{d}$. In this study of Stevia, an irrigation cycle lasts $15 \mathrm{~d}$; and within $0-50 \mathrm{~cm}$ below the ground, the soil moisture content is $11.72 \mathrm{~mm}$, similar to the figure obtained from foreign study of Stevia in seedling stage.

\section{REFERENCES}

[1] X. F. Zhou, Y. H. Wang, and H. X. Zhao, Growth rhythm of some important tree spies. Journal of north-easern forestry institute, 2, 1981, pp.49-59,

[2] C. Q. She, W. X. Yang, and C. L. Lan, Height growth rhythm of cyclocarya paliurus one-year-old seedlings. Forestry Science and Technology, 2, 2009,pp.45-47,.

[3] Z. L. Huang, H. K. Hao, and S. L. Pang, A study on the seedling growth rhythm of Castanopsis hystrix among provenince. Forestry Science and Technology, 3, 2012, pp.24-28.

[4] G. H. Qin, Y. Z. Jiang, and W. D. Wang, Growth rhythm of new poplar clones at juvenile stage. Hebei Journal of Forestry and Orchard Research, 4, 2003, pp.331-335,.

[5] D. D. Soejarto, Botany of Stevia and Stevia rebaudiana. Department of Medicinal Chemistry and Pharmacognosy University of Illinois at Chicago USA, 2002,pp.18-39.

[6] X. H. Zhou, L. N. Chen, and Z. S. Zuo, Advantage effect of development stevia planting and cultivation techniques in Linze county. Agricultural Science and Technology and Information, 23,2009, pp.20-21.

[7] G. M. Wang, Z. B. Hao, and Y. C. Wang, Stevia cultivation techniques in northeast China. Heilongjiang Agricultural Science, 1 2008, pp. 124-126. 
[8] T. C. Li, and X. C. Song, Stevia quality and efficient cultivation techniques in Cool Irrigated Area of Hexi Corridor. Agricultural Science and Technology Communication, 12, 2012, pp. 181-182.

[9] R. F. Li, Standardized production techniques of Stevia rebaudiana Bertoni in southwest Shandong. Sugar Crops of China, 4, 2008, pp. 50-51.

[10] D. Y. Tan, X. M. Chen, and D. B. Wang, Stevia cultivation of winter wheat cropping system technology. Sugar Crops of China, 2, 2000, pp. 59-60

[11] H. G. Liu, and G. D. Liu, Stevia cultivation area in Wuhan Introduction. China Journal of Chinese Materia Medica, 7, 2001, pp.64-65.

[12] K. H. Xu, Z. F. Liu, and J. R. Qiu, Stimulation mechanism and cultivation techniques of black film covering Stevia. Zhejiang Agricultural Science, 5, 2000, pp. 45-46.

[13] Z. X. Zhang, J. F. Yang, and Z. F. Tan, Impact of plant growth regulators on growth and root taking of Stevia rebaudiana. Forest By-Product and Speciality in China, 2, 2008, pp. 13-15.

[14] Y. M. Cao, Z. Y. Miao, and Y. Gao, Stevia revaccination autumn cauliflower supporting cultivation techniques. Shanghai Agricultural Science and Technology, 6, 2009, pp. 102.

[15] H. L. Zheng, Main techniques of planting vegetables after Stevia harvest. Sugar Crops of China, 2, 2006, pp.39-40.

[16] X. Y. Ying, Cuttage growing seedlings and cultivation technique of root / tillering propagation of Stevia rebaudiana in cool irrigated area of Hexi corridor. Sugar Crops of China, 1, 2011,pp.52-54.
[17] K. Ramesh, V. Singh, and N. W. Megeji, Cultivation of Stevia [ Stevia rebaudiana (Bert.) Bertoni]: A Comprehensive Review. Advances in Agronomy, 89, 2006,pp. 137-177.

[18] M. G. Donalisio, F. R. Duarte, and C. J. Souza, Estevia (Stevia rebaudiana). Agrono^-mico, Campinas (Brazil), 34, 1982,pp. 65-68.

[19] C. C. Shock, Experimental cultivation of Rebaudi's stevia in California. Univ. California, Davis Agron. Progr. Rep, 1982 , pp. 122 .

[20] X. L. Tang, Castanopsis hystrix seedling growth rhythm and nursery techniques, Central South University of Forestry and Technology,2010.

[21] S. L. Pang, Z. L. Huang, and H. K. Hao, Analysis on growth dynamics ofCastanopsis fissaseedlings. Forestry Science and Technology,5, 2011,pp.36-39.

[22] L. P. Liu, S. J. Li, and G. Z. Liu, Study on seedling growth rhythm of 25 species excellent broadleaves. Jiangxi Forestry Science and Technology,3, 2001,pp.10-13.

[23] M. V. Chalapathi, S. Thimmegowda, and G. R. Rao, Influence of fertilizer levels on growth, yield and nutrient uptake of ratoon crop of stevia (Stevia rebaudiana). J. Med. Aromatic Plant Sci, 21, 1999, pp.947-949.

[24] D. Fronza, and M. V. Folegatti, Determination of water requirement of Stevia rebaudiana using capillary ascension microlysimeter//Food production, poverty alleviation and environmental challenges as influenced by limited water resources and population growth Volume 1A. 18th International Congress on Irrigation and Drainage, Montréal, Canada, 2002. International Commission on Irrigation and Drainage (ICID), 2002,pp.1-7. 